\title{
Typhoid hepatitis
}

\author{
S.N. Khosla
}

Department of Medicine, Medical College and Hospital, Rohtak, 124001 (Haryana), India

\begin{abstract}
Summary: Liver involvement in typhoid fever is uncommon. Typhoid hepatitis is now being recognized as a definite entity. Over a period of 4 years, we have observed 10 cases $(4.8 \%)$ of typhoid hepatitis out of 210 cases of typhoid fever. Jaundice, anaemia, hepatomegaly and abnormal biochemical tests were present in all cases. Liver biopsy was done in 8 cases and was found to be abnormal in 5 . Two of the 10 cases of typhoid hepatitis died.

Recognition of typhoid hepatitis is important since it has to be differentiated from other common ailments in the tropics such as viral, malarial or amoebic hepatitis. Early institution of specific therapy in cases of typhoid hepatitis carries a good prognosis.
\end{abstract}

\section{Introduction}

Typhoid fever is a common bacterial infection in the tropics attended with considerable morbidity and mortality. ${ }^{1}$ It involves almost all the major systems in the body. Liver involvement may be in the form of hepatomegaly alone, jaundice, biochemical alterations and histopathological changes. ${ }^{2}$ Isolated hepatomegaly usually is of no clinical significance but its occurrence with jaundice though rare, indicates liver involvement as a result of generalized toxaemia or invasion by salmonella organisms. ${ }^{3}$ There are occasional case reports of typhoid hepatitis ${ }^{4-7}$ but detailed studies are lacking.

\section{Materials and methods}

Over a period of 4 years (1984-88) 210 cases of typhoid fever were studied with special reference to liver involvement. Only cases with a clinical profile suggestive of typhoid fever along with rising (four fold) titres of Widal agglutinins on serial estimations and isolation of Salmonella typhi or $S$. paratyphi from blood/bone marrow culture were included.

In every case a detailed clinical history was taken and a thorough physical examination was performed with special reference to hepatosplenomegaly, jaundice, bleeding disorder and stigmata of chronic liver disease. Every attempt was made to exclude cases of viral hepatitis, chronic liver disease and gall bladder disease by history, physical examination and relevant investigations.

Correspondence: S.N. Khosla, M.D., M.N.A.M.S., F.I.A.M.S.

Accepted: 2 July 1990
Investigations included haemoglobin, total and differential leucocyte counts, urine examination (for albumin, sugar, bile salts, bile pigments and urine urobilinogen), bleeding and clotting times, platelet count, peripheral blood film for malarial parasite, hepatitis-B surface antigen in serum, serum transaminases (SGOT/SGPT), serum proteins (total and differential), serum bilirubin, prothrombin time index, serum alkaline phosphatase, 5 -adenosine nucleotidase and plasma fibrinogen levels. Biochemical investigations were carried out serially during the course of the disease and after recovery. Percutaneous liver biopsy was performed (by Menghini's needle) in patients with hepatomegaly, biochemical dysfunction and jaundice after obtaining due consent of the patient. A diagnosis of typhoid hepatitis was considered if a patient fulfilled three or more of the following criteria. (a) Hepatomegaly (liver span $>14 \mathrm{~cm}$ ); (b) jaundice; (c) biochemical abnormalities-serum bilirubin $>30.6 \mu \mathrm{mol} / 1 \mathrm{SGOT} / \mathrm{SGPT}$ raised with or without 5 -adenosine nucleotidase and/or decreased prothrombin time index; (d) abnormal liver histopathology.

\section{Results}

Out of 210 cases of typhoid, 10 cases fulfilled the criteria for typhoid hepatitis. These cases comprised of 6 males and 4 females, their ages ranging from 15-45 years (mean 26.2 years). All cases were culture positive for $S$. typhi, there was no case of $S$. paratyphi. Fever ranging from $102-104^{\circ} \mathrm{F}$ preceded jaundice from 4-30 days. Jaundice, moderate to severe anaemia, hepatomegaly and soft tender splenomegaly were noted in all cases.

Neuropsychiatric features dominated the clinical 
picture in 3 cases and 4 cases had intestinal haemorrhage, out of which 2 cases had intestinal perforation. There were 2 cases of relapse. Two cases $(20 \%)$ out of 10 in the series died. One had intestinal perforation and the other had bleeding from various sources.

All the cases presented with high grade fever, toxaemia and clinical detectable jaundice. The profile presented was in no way different from a very ill patient with typhoid who had no features of hepatitis.

Haemoglobin levels were between $6-9 \mathrm{~g} / \mathrm{dl}$ in 4 cases and $9-11 \mathrm{~g} / \mathrm{dl}$ in 6 cases. Serum protein levels were less than $6 \mathrm{~g} / \mathrm{dl}$ in all cases and the albumin/ globulin ratio was less than 1 .

Platelet count was less than 100,000 in 2 cases and 120,000 in 1 case while in 2 cases bleeding and clotting times were prolonged. Biochemical abnormalities in the form of raised serum bilirubin, SGOT/SGPT, serum alkaline phosphatase, 5'. adenosine nucleotidase and decreased plasma fibrinogen levels, prothrombin time index was observed (Table I). Australia antigen was negative in all cases.

Serial estimation of biochemical parameters showed their return to normal levels after recovery from the acute illness in 8 cases. Histopathology of liver studied in $\mathbf{8}$ cases (consent for biopsy was not available in 2 cases) was abnormal in 5 cases. Cloudy swelling, ballooning degeneration with vacuolation, moderate fatty change, mononuclear cell infiltration in few focal areas with minimal portal tract infiltration without any focal necrosis was observed.

\section{Discussion}

Since the earliest description of hepatic involvement in typhoid by Osler, ${ }^{8}$ who documented enlarged tender liver with clinical jaundice in 8 out of 1500 cases of typhoid fever, a number of studies have appeared. Isolated hepatic enlargement with or without splenomegaly has been reported in $13-65 \%$ cases. $^{9-11}$

Jaundice has been reported in $0.5-7.6 \%$ cases $^{2}$ and we observed it in $4.8 \%$ cases. Hepatomegaly was seen in all cases with jaundice. Stuart and Pullen' observed hepatomegaly in all cases of jaundice in typhoid, yet Ayhan et al. ${ }^{4}$ in their study of 16 cases of typhoid found jaundice in none, hepatomegaly in 7 and histopathological changes in all cases. We have also earlier reported ${ }^{11}$ jaundice without hepatomegaly in cases of typhoid.

Abnormal biochemical tests suggestive of hepatic involvement have been reported in $23-60 \%$ cases. $^{2,9,11,12}$ It has been suggested ${ }^{2,6,12}$ that mild increase in transaminase levels occurs in typhoid hepatitis and it could differentiate such cases from viral hepatitis where increase is marked, yet on the contrary we observed high transaminase levels as did Ayhan et al. ${ }^{4}$

Rise of alkaline phosphatase and 5 -adenosine nucleotidase levels seen in our cases indicates definite involvement of the hepatobiliary system. Out of 3 of our cases with significant hypofibrinogenaemia, low prothrombin index and thrombocytopenia, 1 case manifested with significant bleeding from various sources. Though we had not estimated fibrin degradation products, this could represent bone marrow suppression or liver cell dysfunction. ${ }^{10,13}$

Hepatic encephalopathy, though rare, has been reported in typhoid fever.$^{14}$ However, a variable spectrum of neuropsychiatric manifestations $s^{15}$ could be mistaken for hepatic encephalopathy in cases of typhoid with jaundice though asterexis has not been observed in typhoid encephalopathy. Neuropsychiatric manifestations dominated the clinical picture in 3 of our cases but asterexis was observed in none.

Because of a poor immune response in anaemic and malnourished cases, the complication rate has been found to be higher. ${ }^{1,11}$ Anaemia was observed

Table I Biochemical parameters in cases of typhoid with hepatitis (10 cases) and without hepatitis (200 cases)

\begin{tabular}{lccc}
\hline & Normal value & Hepatitis & Non-hepatitis \\
\hline Serum bilirubin & $5.1-17 \mu \mathrm{mol} / \mathrm{l}$ & $34 \mu \mathrm{mol}-122 \mu \mathrm{mol} / 1$ & $5.1-17 \mu \mathrm{mol} / 1$ \\
SGOT & $3-20 \mathrm{IU}$ & $80-186 \mathrm{IU}$ & $9-40 \mathrm{IU}$ \\
SGPT & $3-15 \mathrm{IU}$ & $80-150 \mathrm{IU}$ & $8-26 \mathrm{IU}$ \\
5 'adenosine & $8.8-22.5 \mathrm{U} / 1$ & $25-92 \mathrm{units} / \mathrm{l}$ & $8.8-10.5 \mathrm{U} / \mathrm{l}$ \\
$\begin{array}{l}\text { nucleotidase } \\
\begin{array}{l}\text { Plasma fibri- } \\
\text { nogen levels }\end{array}\end{array}$ & $200-400 \mathrm{mg} / \mathrm{dl}$ & $100-118 \mathrm{mg} / \mathrm{dl}$ & $200-275 \mathrm{mg} / \mathrm{dl}$ \\
$\begin{array}{l}\text { Prothrombin index } \\
\begin{array}{l}\text { Serum alkaline } \\
\text { phosphatase }\end{array}\end{array}$ & $80-100 \%$ & $50-70 \%$ & $80-100 \%$ \\
\hline
\end{tabular}


in all of our cases.

The relationship of typhoid hepatitis to relapse seems to be more than coincidental. The general incidence of relapse is $12 \%$ while Nasrallah and Nassar ${ }^{12}$ found relapsed typhoid in $57 \%$ of cases of hepatitis and we observed relapse in $20 \%$ of our cases of typhoid hepatitis. Histopathological changes observed by us are similar to those observed by others ${ }^{2,4}$ except that we have not seen any area of focal necrosis (typhoid/Mallory nodules) or bacteria.

Recognition of typhoid hepatitis in the tropics is important as, apart from typhoid, jaundice in a febrile patient in the tropics can be due to viral, amoebic or malarial hepatitis. In viral hepatitis, prodromata in the form of marked anorexia and fever usually precede the acute illness and fever subsides after the appearance of icterus while in typhoid, jaundice occurs at the peak of fever.

\section{References}

1. Khosla, S.N. Changing patterns of typhoid-A reappraisal. Asian Med J 1982, 25: 185-198.

2. Ramachandran, S., Godfrey, J.J. \& Perera, M.V.F. Typhoid hepatitis. JAMA 1974, 230: 236-240.

3. Dagli, A.J., Lulla, S.B. \& Nagle, S.B. Typhoid hepatitis. $J$ Assoc Physicians India 1984, 32: 302-303.

4. Ayhan, A., Gokoz, A. \& Karacadag, S. The liver in typhoid fever. Am J Gastroenterol 1973, 59: 141-146.

5. Rao, P.N., Bhusnurmath, S.R. \& Naik, S.R. Typhoid fever manifesting with haematemesis, hepatitis and haemolysis. $J$ Trop Med Hyg 1978, 81: 146-149.

6. Karr, P., Bhargava, D.K. \& Tandon, B.N. Enteric hepatitis. J Assoc Physicians India 1985, 33: 417-418.

7. Singh, D.S. Typhoid hepatitis. J Assoc Physicians India 1985 , 33: 621 .

8. Osler, W. Hepatic complications of typhoid fever. Johns Hopkins Hosp Rep 1899, 8: 373-387.

9. Stuart, B.M. \& Pullen, R.I. Typhoid-clinical analysis of 360 cases. Arch Ind Med 1946, 78: 629-667.

10. Butler, T., Williams, R. \& Ball, J. Typhoid fever-studies of blood coagulation, bacteremia and endotoxemia. Arch Intern Med 1978, 137: 407-410.

11. Khosla, S.N., Singh, R. \& Singh, G.P. The spectrum of hepatic injury in enteric fever. Am J Gastroenterol 1988, 83: 413-416.
Histopathologically, in viral hepatitis there is acute diffuse inflammation with hepatocyte necrosis without any fatty change. In malarial hepatitis, there is Kupffer cell hyperplasia with brown pigmentation and non-specific granulomatous lesions. Amoebic hepatitis shows focal necrotic areas. ${ }^{16,17}$ The pathogenesis of hepatic involvement in typhoid can be either due to direct invasion of liver by salmonella or else the endotoxins damage hepatocytes with reticulo-endothelial cell hyperplasia. $^{2}$

We are reporting these 10 cases of hepatitis to highlight the occurrence of this clinical entity which should be recognized in any case of fever who develops jaundice at peak of fever with or without hepatomegaly. A correct diagnosis and early institution of specific therapy will improve the prognosis in these cases.

12. Nasrullah, S.M. \& Nassar, V.H. Enteric fever. Am J Gastroenterol 1978, 69: 63-69.

13. Greig, H.B. \& Naidoo, P.D. A case of typhoid fever complicated by severe bleeding syndrome due to deficiency of prothrombin group of coagulating factors. J Trop Med Hyg 1981, 84: 253-257.

14. Faierman, D., Rose, F.A. \& Seckler, S.G. Typhoid fever complicated by hepatitis, nephritis and thrombocytopenia. JAMA 1972, 221: 60-62.

15. Khosla, S.N., Srivastava, S.C. \& Gupta, S.P. Neuropsychiatric manifestations of typhoid. J Trop Med Hyg 1977, 80: 95-98.

16. Sherlock, S. Diseases of the Liver and Biliary System, sixth edition. Blackwell Scientific Publications, Oxford, London, 1981, p. 431-446.

17. Koff, S.R. \& Galambos, J. Viral hepatitis. In: Schiff, L. \& Schiff, E.R (eds) Diseases of the Liver. J.P. Lippincott, Philadelphia, Toronto 1982, p. 461-610. 